\title{
Title: Evolution of lung breathing from a lungless primitive vertebrate
}

\author{
Authors: M. Hoffman ${ }^{\text {a }}$ B. E. Taylor ${ }^{\text {b,c }}$, M. B. Harris ${ }^{\text {a,b,c } * \text {, }}$
}

4 Affiliations:

$5 \quad{ }^{\mathrm{a}}$ Department of Veterinary Medicine, University of Alaska Fairbanks

$6 \quad{ }^{\mathrm{b}}$ Institute of Arctic Biology, University of Alaska Fairbanks.

$7 \quad{ }^{c}$ Department of Biology and Wildlife, University of Alaska Fairbanks

*Correspondence to: Dr. Michael B. Harris, IAB, 902 North Koyukuk Drive, Fairbanks AK,

9 99775-7000; phone: (907)474-7801; fax: (907)474-1932; email: mbharris@alaska.edu

12 Key Words: Lamprey; Breathing; $\mathrm{CO}_{2}$; Evolution; Exaptation; Cough 
13 Abstract:

14 Air breathing was critical to the terrestrial radiation and evolution of tetrapods and arose in fish.

15 The vertebrate lung originated from a progenitor structure present in primitive boney fish. The

16 origin of the neural substrates, which are sensitive to metabolically produced $\mathrm{CO}_{2}$ and which

17 rhythmically activate respiratory muscles to match lung ventilation to metabolic demand, is

18 enigmatic. We have found that a distinct periodic centrally generated rhythm, described as

19 "cough" and occurring in lamprey in vivo and in vitro, is modulated by central sensitivity to $\mathrm{CO}_{2}$.

20 This suggests that elements critical for the evolution of breathing in tetrapods, were present in

21 the most basal vertebrate ancestors prior to the evolution of the lung. We propose that the

22 evolution of breathing in all vertebrates occurred through exaptations derived from these critical

23 basal elements. 


\section{Introduction:}

Air breathing in tetrapods is achieved via lungs, which likely arose from gas-filled bladders functioning for gas exchange and/or buoyancy control in primitive air-breathing fish prior to the radiation of ray-finned (Actinopterygi) and lobe-finned (Sarcopterygi) fishes (Perry et al., 2001; Remmers et al., 2001; Wilson et al., 2000). Air breathing in tetrapods, however, requires more than just a lung. Also required are a "breath", output from a brainstem central rhythm generator $(\mathrm{CRG})$ activating respiratory muscles to ventilate the lung, and populations of brainstem chemoreceptors sensitive to $\mathrm{CO}_{2} / \mathrm{pH}$ that modulate $\mathrm{CRG}$ activity. Together with the lung this system produces breathing matched to metabolic demand. The $\mathrm{CO}_{2} / \mathrm{pH}$-modulated air-breathing $\mathrm{CRG}\left(\mathrm{CRG}_{\mathrm{AB}}\right)$ is anatomically and functionally distinct from the $\mathrm{CRG}$ producing gill ventilation, which is not modulated by $\mathrm{CO}_{2} / \mathrm{pH}$ (Milsom, 2010; Wilson et al., 2002). The origin of the requisite $\mathrm{CO}_{2} / \mathrm{pH}$-modulated $\mathrm{CRG}_{\mathrm{AB}}$ is unknown, but may have preceded the evolution of the lung (Perry et al., 2001).

Lamprey are cartilaginous and jawless fish reminiscent of the basal vertebrate lineage. The larval (ammocoete) stage is considered among the most "primitive" living vertebrates, resembling nonvertebrate chordates. Ammocoetes are microphagous suspension feeders that form burrows in soft sediment. Water flow is generated by continuous rhythmic ventilation of the pharyngeal pouch, which acquires nutrients but also satisfies metabolic gas exchange requirements. $\mathrm{O}_{2}$ diffuses from water across the surface areas of exchange epithelia including the pharynx and gills (Hsia et al., 2013; Mallatt, 1981; Rovainen, 1996), and metabolically produced $\mathrm{CO}_{2}$ easily diffuses across all body surfaces and dissipates into surrounding water. Brainstems isolated from lamprey exhibit rhythmic discharge on cranial nerves that innervate ventilatory muscles. This discharge results from a central rhythm generator for pharyngeal ventilation $\left(\mathrm{CRG}_{\mathrm{P}}\right)(\mathrm{Cinelli}$ et 
al., 2013; Gariépy et al., 2012; Martel et al., 2007; Rovainen, 1996). An additional pattern of periodic activity occurs, characterized as a "slow rhythm" or "cough" (Martel et al., 2007; Rovainen, 1996; Rovainen, 1977). These patterns of putative pharyngeal ventilation and "cough" result from anatomically distinct CRGs and resemble patterns of activity present in isolated brainstems of larval amphibians, which represent the products of distinct CRGs for gill ventilation and a functionally and anatomically distinct tetrapod $\mathrm{CRG}$ for air breathing $\left(\mathrm{CRG}_{\mathrm{AB}}\right)$ (Martel et al., 2007; Missaghi et al., 2013; Wilson et al. 2002). In amphibians and all higher amniotes, the $\mathrm{CRG}_{\mathrm{AB}}$ is responsive to $\mathrm{CO}_{2} / \mathrm{pH}$-sensitive central chemoreceptors that modulate ventilation to meet metabolic demand. The origin of the vertebrate $\mathrm{CRG}_{\mathrm{AB}}$ is unknown and the presence of central $\mathrm{CO}_{2} / \mathrm{pH}$-sensitive chemoreceptors prior to the amphibians is controversial (Milsom, 2010; Wilson et al., 2000). We propose that the lamprey "slow rhythm" or "cough" $\mathrm{CRG}$ is the progenitor to the tetrapod $\mathrm{CRG}_{\mathrm{AB}}$ and test the hypothesis that this progenitor will be modulated by $\mathrm{CO}_{2} / \mathrm{pH}$.

We predict the existence, in the basal vertebrate, of a $\mathrm{CO}_{2} / \mathrm{pH}$-modulated $\mathrm{CRG}$ distinct from that producing gill ventilation. Subsequent evolution of a lung provided the substrates that, through exaptation (Gould and Vrba, 1982) or functional retasking, resulted in the complex combination of lung, chemoreceptor and $\mathrm{CO}_{2} / \mathrm{pH}$-modulated $\mathrm{CRG}_{\mathrm{AB}}$. This new system was then capable of producing and regulating air breathing to meet metabolic demand for ventilation critical for subsequent evolution of amphibians, the transition to terrestrial habitats and further evolution of reptiles, birds, and mammals. Here we show that a $\mathrm{CO}_{2} / \mathrm{pH}$-modulated $\mathrm{CRG}$, distinct from that producing gill ventilation occurs in lamprey, a jawless, lungless and exclusively water-breathing "primitive" fish representative of the basal ancestor common to all vertebrates. We propose this 
$\mathrm{CO}_{2} / \mathrm{pH}$-modulated $\mathrm{CRG}$ represents a critical progenitor characteristic, present in basal vertebrates epochs prior to evolution of the lung.

\section{Methods:}

\section{$\underline{2.1}$ Animals}

Animal use was done in accordance with the guidelines of the "Guide for the Care and Use of Laboratory Animals" of the National Institutes of Health and were approved by the University of Alaska Fairbanks Institutional Animal Care and Use Committee. Animal collection was approved by the State of Alaska Department of Fish and Game. Larval (ammocoete, 7-15 cm, 1$5 \mathrm{~g}$ ) lamprey (Lampetra camtschatica or L. alaskense; Tilesius) were collected through sediment sifting or electroshock, from natural populations occurring in shallow, slow-moving fresh-water streams in interior Alaska. Captive animals were housed at $12{ }^{\circ} \mathrm{C}$ in 20 -liter aquaria containing $3.125 \mathrm{~g}$ salt (Instant Ocean) per L deionized water. Ammocoetes were fed dry yeast three times weekly. Filters were used to maintain water quality and remove excess food. Aquaria were continuously aerated.

\subsection{Isolated-Brainstem Preparation}

Procedures to isolate the brainstem and spinal cord en bloc from ammocoetes, and record from whole nerves associated with ventilation, were slightly modified from those we use to isolate and record from similar tissues derived from larval amphibians (Davies et al., 2009; Taylor and Brundage, 2013; Taylor et al., 2003). Ammocoetes were anesthetized using tricaine methanesulfonate (MS222, Sigma-Aldrich; $0.3 \mathrm{~g} / \mathrm{L}$ in deionized water buffered with $2.4 \mathrm{~g} / \mathrm{L}$ $\mathrm{NaHCO}_{3}$ ) until unresponsive to a tail pinch. Anesthetized animals were transected caudal to the 
branchial pores and the ventral half of the head was removed so the cranium rested on a dissection tray. Subsequent dissection occurred with tissues constantly irrigated with an artificial cerebrospinal fluid (aCSF) equilibrated with $1 \% \mathrm{CO}_{2}$, balance $\mathrm{O}_{2}$ (Davies et al., 2009; Martel et al., 2007). The aCSF comprised (in $\mathrm{mM}$ ) $\mathrm{NaCl}$ (130), $\mathrm{KCl}$ (2.1), $\mathrm{CaCl}_{2}$ (2.6), $\mathrm{MgCl}_{2}$ (1.8), HEPES (4), D-glucose (4), and $\mathrm{NaHCO}_{3}$ (1) buffered to $\mathrm{pH} 7.4$ with $\mathrm{NaOH}$. The dorsal cranium was removed to expose the brain and spinal cord. Each brain was transected at the optic lobes, the spinal cord was cut approximately $5 \mathrm{~mm}$ caudal to obex, and meninges and choroid plexus were removed from regions of the $3^{\text {rd }}$ and $4^{\text {th }}$ ventricles. Remaining cranial and spinal nerves were cut and the decerebrated brainstem was removed en bloc and transferred to an acrylic superfusion recording chamber supplied with aCSF equilibrated with $1.5 \% \mathrm{CO}_{2}$ balance $\mathrm{O}_{2}$. Cranial nerves $\mathrm{V}$ and $\mathrm{X}(\mathrm{CN} \mathrm{V} / \mathrm{X})$ were drawn into glass suction electrodes. Whole-nerve signals were amplified (bipolar recording of whole nerve relative to recording chamber) and filtered (first stage 100x, $10 \mathrm{~Hz}$ low, $1 \mathrm{kHz}$ high, DAM 50, World Precision Instruments (Sarasota, FL, USA); $2^{\text {nd }}$ stage $1000 \mathrm{x}, 100 \mathrm{~Hz}$ low, $1 \mathrm{kHz}$ high, Model 1700 DAC Amplifier, A-M Systems, Carlsborg, WA, USA), and recorded using a computer analogue-to-digital data acquisition system (Powerlab, AD Instruments, Colorado Springs, CO, USA). After dissection, tissues were allowed at least $40 \mathrm{~min}$ to recover. During the experiment, cranial nerve discharge was recorded for 30 min during superfusion with normocapnic aCSF (equilibrated with $1.5 \% \mathrm{CO}_{2}$, balance $\left.\mathrm{O}_{2}\right)$, followed by 10 min hypercapnia $\left(5 \% \mathrm{CO}_{2}\right.$, balance $\left.\mathrm{O}_{2}\right)$, and at least $30 \mathrm{~min}$ of subsequent normocapnia. All experiments were conducted at constant temperatures approximating animal chamber temperature $10-15{ }^{\circ} \mathrm{C}$. 


\subsection{Control Experiments}

116 Each experiment was concluded with tissues exposed to normocapnia subsequent to hypercapnia.

117 Hypercapnic “cough” frequency was reduced during subsequent normocapnia, and was no

118 difference from that during initial normocapnia. Separate trials were conducted during which

119 brainstems were maintained under constant normocapnia. In no case was "cough" frequency

120 observed to increase with time independent of hypercapnic exposure.

\subsection{Data Analysis}

123 Periods for analysis (10 min), for each experiment, were extracted from original data records

124 representing the final period of initial normocapnia, the period of hypercapnia and normocapnia

125 subsequent to hypercapnia. Neurograms were scored for rhythmic patterns of burst activity 126 previously characterized as fictive ventilation of the pharynx (a "fast rhythm") and a distinct

127 periodic burst pattern characterized as a "slow rhythm" or "cough" (Martel et al., 2007;

128 Rovainen, 1996; Rovainen, 1977). The total number of "coughs" occurring during each period 129 was determined and treatment means were statistically assessed.

\subsection{Statistical Analysis}

132 Data were analyzed using repeated measures analysis of variance (RM-ANOVA) comparing

133 "cough" frequency in each preparation during normocapnia and hypercapnia. Where significance

135 method. 


\subsection{Data Exclusion}

The described dataset is derived from 5 in vitro preparations treated with identical protocols. Additional individual replicates had been done but were excluded. One replicate was excluded as it was inadvertently exposed to $2 \% \mathrm{CO}_{2}$ during "normocapnia" prior to the $5 \%$ hypercapnia (rather than 1.5\%); three replicates were excluded because tissues received a different treatment followed by a prolonged recovery prior to the hypercapnic exposure trial; one replicate was excluded because experiments were conducted in a different recording apparatus using recirculated solutions (Wilson et al., 1999). None of these differences would be expected to confound the experiment and, were these trials included, we would still find a statistically significant increase in "cough" frequency with hypercapnia $(N=10 ; P=0.007 ; N C v s . H C$ $P=0.011, t=3.371 ; H C v s . R N C, P=0.018, t=2.943,1$-way $R M A N O V A)$. Fictive pharyngeal ventilation was relatively regular and appeared consistent within each preparation. However, the amplitude was variable and at times individual bursts were difficult to distinguish from background. The occurrence of "cough" appeared to influence subsequent pharyngeal ventilation. The variability and potential complexity of this pattern prevented detailed quantification and, as the focus of the investigation was on the "cough" pattern, pharyngeal ventilation is not considered beyond cursory observation that there were no consistent frequency changes with hypercapnic exposure.

\subsection{Whole-Animal Plethysmography}

Twelve roughly equal sized (1.0-2 g) ammocoetes were individually identified and placed into aerated individual 1-liter aquaria that were visually isolated from one another and maintained at $12{ }^{\circ} \mathrm{C}$. 
160 For plethysmography, animals were placed in a transparent acrylic tube $(1 \mathrm{~cm}$ i.d., $30 \mathrm{~cm}$ long)

161 attached at one end to a customized resistance pneumotachograph and open at the other end. The

162 pneumotachograph was fabricated from two short $(7-10 \mathrm{~mm})$ cylinders constructed from thick-

163 walled, $5 \mathrm{~mm}$ i.d. acrylic tube, each fitted with a $1 \mathrm{~cm}$ length of 18 gauge steel tube to access the

164 inner diameter through the tube wall. The two cylinders were joined in series with cyanoacrylate

165 adhesive, in opposition to a mesh resistance barrier (300 $\mu$ m nylon net) separating the two. Two

166 poles of a water-filled differential pressure transducer (Validyne DP-45; $2 \mathrm{~cm} \mathrm{H}_{2} \mathrm{O}$ pressure

167 diaphragm; Validyne Engineering, Northridge CA, USA) were connected across the resistance

168 with water-filled polyethylene tubing. Prior to experiments, the pneumotachograph was attached

169 to the transparent tube with hot glue. In this configuration, water flowing across the resistance

170 produced a differential pressure, measured by the transducer. The pneumotachograph was not

171 calibrated for absolute flow measurements, but accurately reflected relative flow patterns. The

172 magnitude of the differential pressure was proportional to water flow, with polarity indicative of

173 inward or outward direction of flow (Fig 2).

Ammocoetes were positioned close to the pneumotachograph and often spontaneously placed the vestibular openings to their pharynx within the pneumotachograph itself, greatly enhancing measurement resolution.

The tube was placed in a partially filled, temperature-controlled aquarium $\left(13^{\circ} \mathrm{C} \pm 1{ }^{\circ} \mathrm{C}\right)$ aerated from a controlled gas supply that allowed mixing of $\mathrm{CO}_{2}$ and air. Aeration was achieved using a spherical aluminum gas diffuser stone placed approximately $2 \mathrm{~cm}$ beyond the pneumotachograph. Ammocoetes acclimated for 20 min prior to experimentation, with aeration by air $\left(0 \% \mathrm{CO}_{2}\right)$. Experiments consisted of a 30 -min period of observation when the aquarium continued to be aerated with either air, $3 \%$ or $5 \% \mathrm{CO}_{2}$ mixtures (balance air). Gas mixture 
183

184

185

186

composition was confirmed by sampling mixed gas through a $\mathrm{CO}_{2}$ analyzer (Capnomac; Datex Instrument Corporation, Helsinki Finland). Aquatic $\mathrm{pH}$ was not measured. Gas treatments in a given experiment were randomized, and each individual was exposed to each gas treatment by repeating experiments on subsequent days. Only one treatment was administered to an individual on a single day.

The pressure transducer output was demodulated and amplified (CD15; Validyne Engineering, Northridge CA, USA), and recorded using a computer analogue-to-digital data acquisition system (Powerlab, AD Instruments, Colorado Springs, CO, USA). Ammocoetes were simultaneously visually monitored within transparent tubes from below the glass aquarium using a USB digital microscope (MicroXplore PC200, Orion Telescopes, Watsonville CA, USA). Continuous digital video records were acquired and synchronized with pressure recordings. The experimental apparatus was illuminated from above, allowing body movements and ventilation to be resolved from the video record and matched to patterns of pressure generation.

\subsection{Data Analysis}

Data records were de-identified with respect to subject and experimental treatment, so that data analysis was blinded. Pressure recordings and video records were scored for patterns representative of pharyngeal ventilation or cough. The total number of coughs per 30-min experimental period was determined for each trial. Data were then re-identified, tabulated and statistically assessed. 


\subsection{Statistical Analysis}

206

Data were analyzed using repeated measures analysis of variance (RM-ANOVA), comparing "cough" frequency in each individual subject between trials with exposure to normocapnia and hypercapnia. Where significant difference was found, RM-ANOVAs were followed by HolmSidak post-hoc multiple comparison analysis.

\subsection{Interpretation}

Ventilatory water flows were interpreted from pneumotachograph pressure fluctuations measured at the anterior of the animal. Pressure measurements during pharyngeal pouch ventilation matched expected patterns, as ammocoete ventilation is unidirectional with water being drawn past the pneumotachograph resistance into the mouth, passing through the branchial pores (Mallatt, 1981; Rovainen, 1996) and flowing caudally through the unrestricted distal end of the tube. In ammocoetes, "inspiratory" unidirectional water flow is primarily generated by movement of an internal vellum drawing water into the mouth and pharynx, back through the branchial basket and out through the branchial pores, augmented at times by compression of the branchial basket (Mallatt, 1981; Rovainen, 1996; Rovainen and Schieber, 1975). Movement of the vellum and branchial basket were easily observable in the transilluminated animal within the transparent tube.

We did not attempt to quantify ventilatory volumes as the amplitude of the pressure deflection during rhythmic pharyngeal ventilation varied not only with apparent ventilatory effort but also with the position of the ammocoete with respect to the pneumotachograph. Pressure signals were synchronized with visible movements of the vellum, as expected by the vellum acting as 
227 the primary pump (Mallatt, 1981; Rovainen, 1996). At times movements of the vellum were coordinated with branchial basket compression. Subjectively, pressures measured during rhythmic tidal pharyngeal ventilation were relatively uniform. Pressures generated during rhythmic pharyngeal ventilation were short, monophasic and negative at the internal face of the resistance with respect to the outer face (Fig 2A upper trace). This pressure profile is consistent with a negative pressure generated in the pharyngeal pouch by the velum drawing a volume of water into the tube across the resistance. Supplemental compression of the branchial basket to augment stroke volume through the branchial pores would not influence recorded pressure at the anterior of the animal.

Mechanical changes associated with periodic "cough" were not quantified although, subjectively, "cough" was always observed in association with large branchial basket compression. Presumably, vellar movements were also altered during "cough". Pressures measured during periodic "cough" suggested a seemingly normal inspiratory loading followed by a larger amplitude and slightly longer duration pressure pulse, positive at the internal face of the resistance with respect to the outer face (Fig 2A upper trace). This profile is consistent with a positive pressure generated in the pharyngeal pouch and/or branchial basket forcing a volume of water anteriorly from the vestibular opening and out across the resistance. Although not quantified, the area of the positive pressure deflection associated with the "cough" was noticeably greater than that of the negative pressure typical of unidirectional tidal pharyngeal ventilation. This would suggest that the stroke volume of pharyngeal ventilation (presumably approximating pharyngeal pouch volume) is exceeded during the "cough", and may indicate contributions from compression of the branchial basket cavity to the volume of the "cough". As 
249 water flows were only measured at the anterior of the animal, measurements do not show

250 whether or not water was also expelled through the branchial pores during "cough".

251 With respect to the example pressure tracings (Fig 2A) the large negative pressure deflection 252 subsequent to the illustrated "cough" may represent post-"cough" expansion of the branchial 253 cavity contributing additional volume to the subsequent inspiration, or possible slight caudal 254 movement of the animal acting as a piston and drawing water into the tube. Apparent 255 differences in pressure deflections associated with pharyngeal stroke volume before and after a 256 “cough" were not quantified.

\subsection{Data Exclusion}

259 In order to remove possible confounding influence of mechanosensory input influencing cough 260 (Martel et al., 2007; Rovainen, 1977), trials in which debris was visible within or proximal to the 261 pharyngeal basket, regardless of cough expression, were excluded from the data set. In such 262 cases, data records were re-identified and trials were repeated with data then de-identified and 263 analyzed blind. Data from two additional trials were excluded for high cough frequencies, 264 characteristic of mechanically induced cough (Martel et al., 2007; Rovainen, 1977), although the 265 source of this stimulation was not identified. 


\section{Results:}

Ammocoete brainstems were isolated and activity was recorded from cranial nerves, which innervate structures generating rhythmic pharyngeal ventilation (Fig 1A). With normocapnia, cranial nerve discharge exhibited regular and rhythmic burst patterns representative of pharyngeal pouch ventilation, with irregular, periodic and distinct "cough" (Fig 1B) (Hsia et al., 2013; Martel et al., 2007; Rovainen, 1996; Rovainen, 1977). Isolated brainstems were exposed to normocapnia $\left(\mathrm{NC} ; 1.5 \% \mathrm{CO}_{2}\right)$ and hypercapnia $\left(\mathrm{HC} ; 5 \% \mathrm{CO}_{2}\right)$. Burst patterns were analyzed for event frequency in 10-minute periods immediately prior to and after the gas change, and with recovery following a return to $\mathrm{NC}(\mathrm{RNC}$; Fig $1 \mathrm{C})$. Elevating $\mathrm{CO}_{2}$ increased the frequency of “cough" (event/10 min; $\mathrm{N}=5 ; \mathrm{P}=0.02 ; \mathrm{NC}$ vs. $\mathrm{HC} \mathrm{P}=0.031, \mathrm{t}=3.32 ; \mathrm{HC}$ vs. $\mathrm{RNC}, \mathrm{P}=0.037, \mathrm{t}$ =2.937, 1-way RMANOVA).

Intact ammocoetes (in vivo) were placed in a clear tube, and patterns of pharyngeal ventilation were recorded by measuring the differential pressure produced by water flowing across a fine mesh resistance ahead of the animal (Fig 2A). Water flow patterns generated by intact lamprey ammocoetes in vivo, matched previous characterizations of rhythmic unidirectional pharyngeal ventilation; loading the anterior pharyngeal pouch through caudal movement of a velum, and expulsion of water caudally through lateral branchial pores (Mallatt, 1981; Rovainen, 1996).

\section{During pharyngeal ventilation, water flow was cyclic and unidirectional.}

Exposing ammocoetes to elevated aquatic $\mathrm{CO}_{2}$ had no apparent effect on pharyngeal ventilation, but stimulated a formerly infrequent and distinct water flow pattern of tidal "cough" (Fig 2 B); a seemingly normal loading of the pharyngeal pouch was followed by forceful anterior expulsion of water from the pouch in a reverse direction across the mesh resistance. The reconfiguration of active elements resulting in this different flow pattern is unknown. The frequency of "cough" 
was determined during randomized 30-minute periods when water was equilibrated with 0,3 , or

$2915 \% \mathrm{CO}_{2}$ (balance air). “Cough” frequency was enhanced by hypercapnia (event/30 min; $\mathrm{P}=0.034, \mathrm{~F}=4.215$, 1-way RMANOVA; Holm-Sidak MCP, 0 vs 3\% $\mathrm{P}=0.6, \mathrm{t}=0.535, \mathrm{n}=9$; 0 vs $5 \% \mathrm{P}=0.030, \mathrm{t}=2.714, \mathrm{n}=9)$. Elevated aquatic $\mathrm{CO}_{2}$ also agitated ammocoetes and induced large body movements and swimming.

\section{Discussion:}

Our results indicate that the anatomically distinct CRG for the slow rhythm/“cough" in larval

298 lamprey is modulated by $\mathrm{CO}_{2} / \mathrm{pH}$. Furthermore we show that "cough" is stimulated in vivo in response to aquatic hypercapnia and that animals become agitated under these conditions. Observations identify central $\mathrm{CO}_{2} / \mathrm{pH}$ chemosensitivity in vitro and complimentary responsiveness of the intact animal.

Small filter feeding lamprey ammocoetes generate water currents by continuous rhythmic pharyngeal pouch ventilation to supply nutrients and, in so doing, satisfy gas exchange requirements as $\mathrm{O}_{2}$ and $\mathrm{CO}_{2}$ diffuse between water and large surface areas of exchange epithelia including the pharynx and gills (Hsia et al., 2013). It may seem curious that a $\mathrm{CO}_{2} / \mathrm{pH}-$ modulated CRG would occur in an organism where gas exchange needs are generally satisfied

307 by water currents produced during feeding, and in an aquatic environment that normally poses no 308 limitation to $\mathrm{CO}_{2}$ excretion. Consider, however, that lamprey ammocoetes commonly inhabit 309 narrow tube burrows dug in soft sediments. Substrate can occlude burrow entrances and limit 310 water flow. Metabolically produced $\mathrm{CO}_{2}$, which normally dissipates into water, would build up 311 in an occluded burrow. Thus, a $\mathrm{CO}_{2} / \mathrm{pH}$-modulated $\mathrm{CRG}$ that induces "cough" would be 312 adaptive. Forceful "coughs" and agitation of the whole animal would contribute to maintaining a 
313 patent opening and/or prompt the animal to evacuate a collapsing burrow. Ammocoete

314 ventilation is modulated by aquatic $\mathrm{O}_{2}$ availability and stimulated by hypoxia (Rovainen 1996).

315 Aquatic hypoxia is common and it may be that despite ventilatory sensitivity to hypoxia, $\mathrm{CO}_{2}-$

mediated initiation of cough provides for an alarm response to burrow occlusion with better

317 sensitivity than would a response initiated by hypoxia alone.

318 The presence, in the most basal vertebrate, of a $\mathrm{CO}_{2} / \mathrm{pH}$-modulated $\mathrm{CRG}$ distinct from that 319 producing rhythmic pharyngeal ventilation provides insight into the evolution of ventilatory 320 control and the conservation of basic control mechanisms across vertebrate lineages. Our 321 findings support the following hypothetical model wherein mechanisms common and critical to

vertebrate breathing arose through exaptation (Gould and Vrba, 1982) from those present in the basal vertebrate ancestor (Fig 3).

Represented by the lamprey ammocoete, basal vertebrates possessed two distinct CRGs. One CRG generated rhythmic ventilation of the pharynx and branchial basket and produced a water current for filter feeding that also satisfied gas exchange needs $\left(\mathrm{CRG}_{\mathrm{P}}\right)$ (Hsia et al., 2013). A second and distinct $\mathrm{CO}_{2} / \mathrm{pH}$-modulated $\mathrm{CRG}_{\text {cough }}$ produced water flows to clear debris from filter feeding areas, aided in maintaining patent exchange surfaces and chambers in the animal's habitat, and responded when chamber water exchange was restricted. The evolution of jaws in gnathostomes separated feeding and gas exchange (Mallatt, 1996). A first exaptation occurred when the rhythmic $\mathrm{CRG}_{\mathrm{P}}$-driven pharyngeal pump for filter feeding was retasked generating rhythmic continuous gill ventilation for gas exchange $\left(\mathrm{CRG}_{\mathrm{P}}\right.$ becomes the $\left.\mathrm{CRG}_{\text {gill }}\right)$. The progenitor CRG for "cough" was retained to produce forceful water currents functioning to clear delicate gill structures. Bimodal ventilation with the evolution of the lung in primitive fish (and represented by extant lunged fish and larval amphibians) involved continued recruitment of the 
$\mathrm{CRG}_{\text {gill }}$ for gill ventilation, along with a second exaptation; retasking the $\mathrm{CRG}_{\text {cough }}$ to function as the $\mathrm{CRG}$ for air-breathing $\left(\mathrm{CRG}_{\mathrm{AB}}\right)$. The existing $\mathrm{CO}_{2} / \mathrm{pH}$ modulation of the $\mathrm{CRG}_{\mathrm{cough}} / \mathrm{CRG}_{\mathrm{AB}}$ allowed periodic lung ventilation to respond to requirements imposed by metabolically produced $\mathrm{CO}_{2}$. The $\mathrm{CRG}_{\mathrm{AB}}$ retained this function in adult amphibians, while the $\mathrm{CRG}_{\text {gill }}$ generates rhythmic ventilation of the buccal cavity contributing to ventilation, olfaction and vocalization despite the resorption of gills. Air breathing in reptiles, birds and mammals derives from the $\mathrm{CO}_{2} / \mathrm{pH}$-modulated $\mathrm{CRG}_{\mathrm{AB}}$, producing periodic air breathing in ectothermic tetrapods with increasing frequency as metabolic demand increases. The high metabolism of endotherms dictates that the $\mathrm{CRG}_{\mathrm{AB}}$ is continuously active. In "higher" amniotes a third exaptation retasked the $\mathrm{CRG}_{\text {gill }}$ to produce the high frequency, although periodic, rhythms underlying gular fluttering in reptiles and birds, and suckling in mammals.

We propose that the motor pattern produced by the ancestral $\mathrm{CRG}_{\text {cough }}$ facilitated exaptation to air breathing. Fish are commonly reported to "cough", presumably as a result of the distinct $\mathrm{CRG}_{\text {cough }}$ (Ballintijn, 1985; Ballintijn and Jüch, 1984; Ballintijn and Punt, 1985;; Burleson and Smith, 2001), and there is evidence that "cough" in fish can be modulated by acidity (Bishop and McIntosh, 1981; Hargis, 1976; Lunn et al., 1976; Nevitt 1991; Rose-Janes and Playle, 2001; Ross et al. 2001; Satchell and Maddalena, 1972). Our model predicts that exaptation retasked the $\mathrm{CRG}_{\text {cough }}$ with the evolution of air breathing in tetrapods, making absent the ancestral mechanism of cough. It is apparent that amphibians and reptiles do not "cough" (presumably as these groups lack a $\mathrm{CRG}_{\text {cough }}$ ). The irritant receptor mediated activity known as "cough" in mammals (Brooks, 2011; Canning, 2008) is a newly derived and distinct reflex seemingly mechanistically unrelated to the ancestral $\mathrm{CRG}_{\text {cough }}$. 


\section{Concluding Remarks:}

360 Our results illustrate the presence of a central $\mathrm{CO}_{2} / \mathrm{pH}$-sensitive chemoreceptor in lamprey,

361 consonant with such presence in the common ancestor to all vertebrates. Lamprey possess a

$362 \mathrm{CO}_{2} / \mathrm{pH}$-sensitive $\mathrm{CRG}$, the presence of which in basal vertebrates may have provided the 363 substrate critical for the evolution of vertebrate air breathing.

\section{Acknowledgments:}

366 We thank Dr. Trent Sutton and Dr. Andrew Seitz for assistance in acquiring research animals.

367 Funding: This work was funded by the National Institutes of Health [2U54NS041069 to MBH and BET] and the National Science Foundation [IOS 1022442 to BET]. analysis and interpretation $\mathrm{MBH}, \mathrm{MH}$; Manuscript preparation $\mathrm{MBH}, \mathrm{MH}, \mathrm{BET}$. Correspondence and requests for materials should be addressed to mbharris@alaska.edu 
90

\section{References:}

Ballintijn, C. M., 1985. The respiratory function of gill filament muscles in the carp. Respir Physiol. 60(1), 59-74.

Ballintijn, C. M., Punt, G. J., 1985. Gill arch movements and the function of the dorsal gill arch muscles in the carp. Respir Physiol. 60(1), 39-57.

Ballintijn, C. M., Jüch, P. J., 1984. Interaction of respiration with coughing, feeding, vision and oculomotor control in fish. Brain Behav Evol. 25(2-3), 99-108.

Bishop, W. E., McIntosh, A. W., 1981. Acute lethality and effects of sublethal cadmium exposure on ventilation frequency and cough rate of bluegill (Lepomis macrochirus). Arch Environ Contam Toxicol. 10(5), 519-30.

Brook, S. M., 2011. Perspective on the human cough reflex Cough. 7,10.

Burleson, M. L., Smith, R. L., 2001. Central nervous control of gill filament muscles in channel catfish. Respir Physiol. 126(2),103-12.

Canning, B. J., 2008. The cough reflex in animals: relevance to human cough research. Lung. 186 Suppl 1, S23-8. 
394 Cinelli, E., Robertson, B., Mutolo, D., Grillner, S., Pantaleo, T., Bongianni, F., 2013. Neuronal

395 mechanisms of respiratory pattern generation are evolutionary conserved. J Neurosci. 33(21),

396 9104-12.

397

398

399 pattern generation in the bullfrog: role of neurokinin-1 and mu-opioid receptors.

400 J Comp Physiol B. 179(5), 579-92.

401

402 Gariépy, J. F., Missaghi, K., Chartré, S., Robert, M., Auclair, F., Dubuc, R., 2012. Bilateral

403 connectivity in the brainstem respiratory networks of lampreys. J Comp Neurol. 520(7), 1442-56.

404

405

406

Hargis, J. R., 1976. Ventilation and metabolic rate of young rainbow trout (Salmo gairdneri) exposed to sublethal environmental pH. J Exp Zool. 196(1), 39-44.

407

408

409

410

Hsia C. C., Schmitz A., Lambertz M., Perry S. F., Maina J. N., 2013. Evolution of air breathing: oxygen homeostasis and the transitions from water to land and sky. Compr Physiol. 3(2), 849915.

411

412 Lunn, C. R., Toews, D. P., Pree, D. J., 1976. Effects of three pesticides on respiration, coughing, 413 and heart rates of rainbow trout (Salmo gairdneri Richardson). Can J Zool. 54(2), 214-9.

414

415 Mallatt, J., 1996. Ventilation and the origin of jawed vertebrates: a new mouth. Zool J. Linnean 416 Soc. $117,329-404$. 
418 Mallatt, J., 1981. The suspension feeding mechanism of the larval lamprey petromyzon marinus.

419 J. Zool. Lond. 194, 103-142.

420

421 Martel, B., Guimond, J. C., Gariépy, J. F., Gravel, J., Auclair, F., Kolta, A., Lund, J. P., Dubuc, 422 R., 2007. Respiratory rhythms generated in the lamprey rhombencephalon. Neuroscience.

$423 \quad 148(1), 279-93$.

424

Missaghi, K., Auclair, F., Dubuc, R., 2013. On the organization and location of the generator for the slow respiratory rhythm in lampreys. 782.22. Neuroscience Meeting Planner. San Diego CA:

427 Society for Neuroscience. Online.

428

429

430

Milsom, W. K., 2010. The phylogeny of central chemoreception. Respir Physiol Neurobiol. 173, $195-200$.

431

432 Nevitt, G. A., 1991. Do fish sniff? A new mechanism of olfactory sampling in pleuronectid 433 flounders. J Exp Biol. 157, 1-18.

434

435 Perry, S. F., Wilson, R. J., Straus, C., Harris, M. B., Remmers, J. E., 2001. Which came first, the 436 lung or the breath? Comp Biochem Physiol A Mol Integr Physiol. 129, 37-47. 
438 Remmers, J. E., Torgerson, C., Harris, M., Perry, S. F., Vasilakos, K., Wilson, R. J., 2001.

439 Evolution of central respiratory chemoreception: a new twist on an old story. Respir Physiol.

$440 \quad 129(1-2), 211-7$.

441

442 Rose-Janes, N. G., Playle, R. C., 2000. Protection by two complexing agents, thiosulphate and 443 dissolved organic matter, against the physiological effects of silver nitrate to rainbow trout 444 (Oncorhynchus mykiss) in ion-poor water. Aquat Toxicol. 51(1), 1-18.

445

446 Ross, R. M., Krise, W. F., Redell, L. A., Bennett, R. M., 2001. Effects of dissolved carbon

447 dioxide on the physiology and behavior of fish in artificial streams. Environ Toxicol. 16(1), 84-

44895.

449

450

Rovainen, C. M.,1996. Feeding and breathing in lampreys. Brain Behav Evol. 48(5), 297-305.

451

452 Rovainen, C. M., 1977. Neural control of ventilation in the lamprey. Fed Proc. 36(10), 2386-9.

453

454 Rovainen, C. M., Schieber, M. H., 1975. Ventilation of larval lampreys. J. Comp. Physiol. 104, $455 \quad 185-203$.

456

457 Satchell, G. H., Maddalena, D. J., 1972. The cough or expulsion reflex in the Port Jackson shark, 458 Heterodontus portusjacksoni. Comp Biochem Physiol A Comp Physiol. 41(1), 49-62. 
460 Taylor, B. E., Brundage, C. M., 2013. Chronic, but not acute, ethanol exposure impairs central 461 hypercapnic ventilatory drive in bullfrog tadpoles. Respir Physiol Neurobiol. 185(3), 533-42.

462

463 Taylor, B. E., Harris, M. B., Leiter, J. C., Gdovin, M. J., 2003. Ontogeny of central $\mathrm{CO}_{2}$

464 chemoreception: chemosensitivity in the ventral medulla of developing bullfrogs. Am J Physiol

465 Regul Integr Comp Physiol. 285, R1461-72.

466

467 Wilson, R. J. A., Taylor, B. E., Harris, M. B., 2009. Evolution of vertebrate respiratory neural

468 control. In: Encyclopedia of Neuroscience ( $4^{\text {th }}$ Ed.), Adelman G and Smith BH (Eds). Elsevier

469 Ltd. 67-75.

470

471 Wilson, R. J., Vasilakos, K., Harris, M. B., Straus, C., Remmers, J. E., 2002. Evidence that

472 ventilatory rhythmogenesis in the frog involves two distinct neuronal oscillators. $J$ Physiol

473 (Lond). 540, 557-70.

474

475

476

Wilson, R. J. A., Harris, M. B., Remmers, J. E., Perry, S. F., 2000. Evolution of air-breathing and central $\mathrm{CO}_{2} / \mathrm{H}^{+}$sensitivity: New insights from an old fish. $J$ Exp Biol. 203, 3505-3512.

477

478 Wilson, R. J., Straus, C., Remmers, J. E., 1999. Efficacy of a low volume recirculating 479 superfusion chamber for long term administration of expensive drugs and dyes. J Neurosci 480 Methods. 87(2), 175-84. 
Fig 1. In vitro experiments. Ammocoete brainstems were isolated and exposed to normocapnia $\left(1.5 \% \mathrm{CO}_{2}\right)$ and hypercapnia $\left(5 \% \mathrm{CO}_{2}\right)$ to investigate the "cough" $\mathrm{CRG}$ response. Activity was

484

485

486 recorded from intact cranial nerve roots of the in vitro brainstem, which normally innervate structures generating rhythmic pharyngeal ventilation (A; CN V, VII and X illustrated). With normocapnia, cranial nerve discharge (CN VII shown) exhibited regular and rhythmic burst patterns representative of pharyngeal pouch ventilation (top), with irregular, periodic and distinct “cough" (bottom; Hsia et al., 2013; Martel et al., 2007; Rovainen, 1977) indicated by arrows (B). Data were analyzed for event frequency in 10-minute periods immediately prior to (NC) and after $(\mathrm{HC})$ the gas change, and with recovery following a return to $\mathrm{NC}(\mathrm{RNC} ; \mathrm{C})$. Elevating $\mathrm{CO}_{2}$ increased the frequency of "cough" $(\mathrm{n}=5 ; \mathrm{P}=0.02 ; \mathrm{NC}$ vs. HC P=0.031, t=3.32; HC vs. RNC, $\mathrm{P}=0.037, \mathrm{t}=2.937,1$-way RMANOVA).

Fig 2. In vivo experiments. Intact ammocoetes were placed in a clear tube (A). In vivo pharyngeal ventilation and "cough" were recorded by measuring the differential pressure (dP) produced by water flowing across a fine mesh resistance ahead of the animal. Water flow patterns were distinct between the two behaviours. During pharyngeal ventilation, water flow is cyclic and unidirectional. Movement of a velum in the anterior pharynx draws water across the mesh resistance while loading this cavity, and propels it caudally through a branchial basket and lateral branchial pores (Martel et al., 2007; Rovainen, 1977), and out the open distal end of the tube. Exposing ammocoetes to elevated aquatic $\mathrm{CO}_{2}$ stimulated a formerly infrequent and distinct water flow pattern of tidal "cough" (arrow); a seemingly normal loading of the 
503 pharyngeal pouch followed by forceful anterior expulsion of water from the pouch in a reverse

504 direction across the mesh resistance. The frequency of cough (B) was determined during

505

506

507

508

509

510

511

512

513

514

515

516

517 randomized 30-minute periods when water was equilibrated with either 0,3 , or $5 \% \mathrm{CO}_{2}$ (balance air). "Cough" frequency was enhanced by hypercapnia ( $\mathrm{P}=0.034, \mathrm{~F}=4.215$, 1-way RMANOVA; Holm-Sidak MCP, 0 vs. $3 \% \mathrm{P}=0.6, \mathrm{t}=0.535, \mathrm{n}=9 ; 0$ vs. $5 \% \mathrm{P}=0.030, \mathrm{t}=2.714, \mathrm{n}=9$ ).

Fig 3. Evolution of Air-Breathing Central Rhythm Generator. Schematic illustration of the speculative evolution of ventilatory rhythm control in vertebrates: basic elements critical for ventilatory control and producing phasic pharyngeal basket ventilation and periodic "cough" were present in a basal, common vertebrate ancestor. These elements transition during vertebrate evolution through a process of exaptation or functional retasking. Mechanisms generating rhythmic pharyngeal ventilation are exapted to produce gill ventilation, buccal cavity ventilation, gular fluttering and suckling. Distinct mechanisms producing "cough" are sensitive to $\mathrm{CO}_{2}$ and are exapted to produce air breathing. In this scheme, as described in the text, pharyngeal pumping in the basal vertebrate resulted from the pool of pump muscle motor neurons (MNP) being activated by relatively continuous activity from a central rhythm generator $(\mathrm{CRG}, \sim)$ generating a pharyngeal ventilatory rhythm and, periodically by a distinct $\mathrm{CO}_{2} / \mathrm{pH}$-modulated $\mathrm{CRG}_{\text {cough }}$ producing water flows to clear debris from filter feeding areas and habitat. A first exaptation occurred with the evolution of unimodal gill ventilation when the pharyngeal pump was retasked to generate rhythmic gill ventilation $\left(\mathrm{CRG}_{\mathrm{P}}\right.$ becomes the $\left.\mathrm{CRG}_{\text {gill }}\right)$ and the $\mathrm{CRG}_{\text {cough }}$ was retained. A second exaptation facilitated bimodal gill and air breathing; a retasked $\mathrm{CO}_{2} / \mathrm{pH}$ modulated $\mathrm{CRG}_{\text {cough }}$ functions as the $\mathrm{CRG}$ for air-breathing $\left(\mathrm{CRG}_{\mathrm{AB}}\right)$, while the $\mathrm{CRG}_{\text {gill }}$ is 
525 retained for gill ventilation. Unimodal air breathing continued to be generated by the $\mathrm{CO}_{2} / \mathrm{pH}$

526 modulated $\mathrm{CRG}_{\mathrm{AB}}$ in reptiles, birds and mammals, while the $\mathrm{CRG}_{\text {gill }}$ is retasked to produce

527 periodic rhythmic gular fluttering and suckling. 

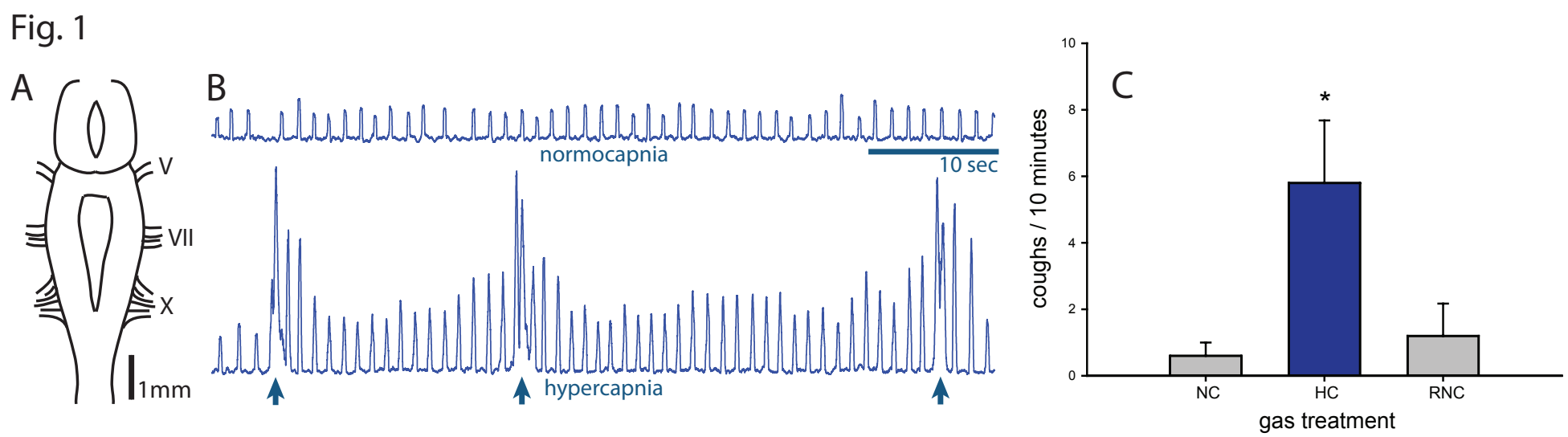
Fig. 2

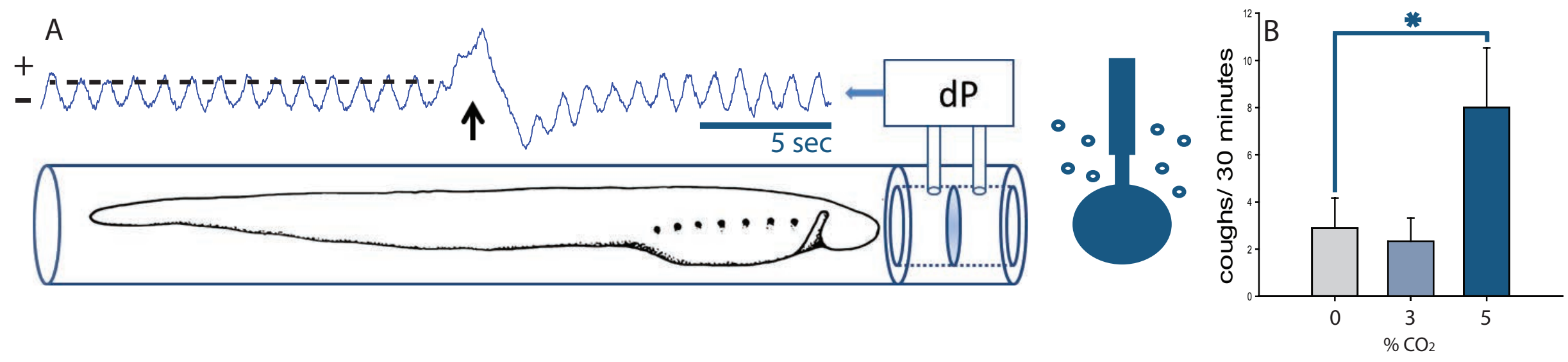


Fig. 3

Pharyngeal pumping

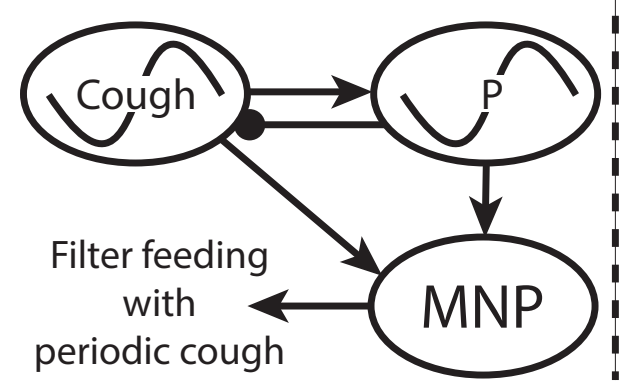

Unimodal gill ventilation

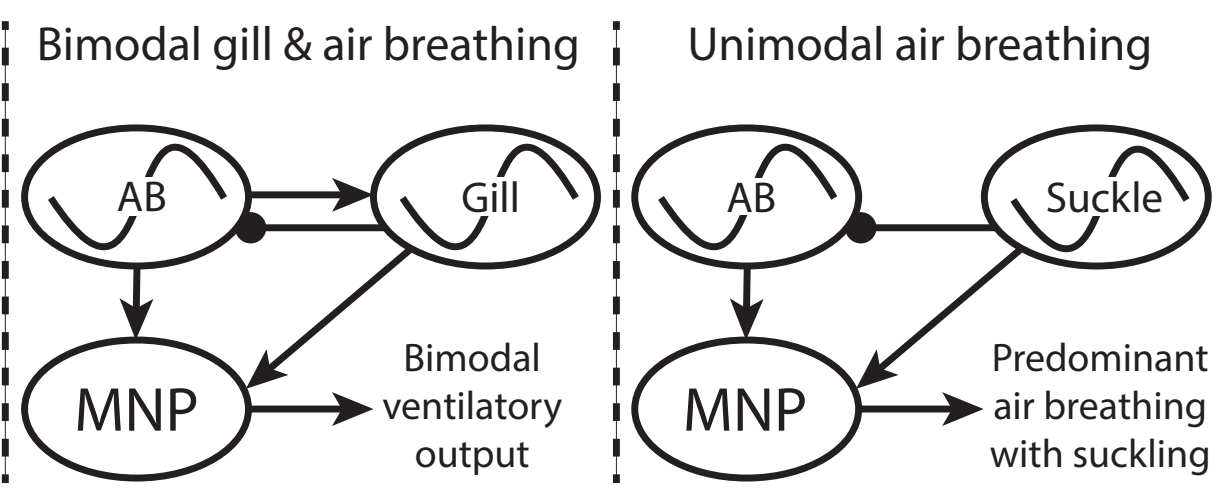

